\title{
Pseudomonas Spp. can Inhibit Streptomyces scabies Growth and Repress the Expression of Genes Involved in Pathogenesis
}

\author{
Renee St-Onge ${ }^{1}$, Claudia Goyer ${ }^{2}$ and Martin Filion ${ }^{1 *}$ \\ ${ }^{1}$ Université de Moncton, Campus de Moncton, Département de biologie, Moncton, NB, Canada, E1A 3E9 \\ ${ }^{2}$ Potato Research Center, Agriculture and Agri-Food Canada, Fredericton, NB, Canada, E3B $4 Z 7$
}

\begin{abstract}
Common scab, caused by Streptomyces scabies, is an economically important disease affecting potato crops worldwide. Confirmed and putative pathogenicity- and virulence-related factors, including the phytotoxic thaxtomins, the necrosis protein Nec1 and the tomatinase TomA, have been characterized in S. scabies. Using plate inhibition assays, the ability of three antimicrobial metabolite-producing Pseudomonas strains (LBUM 223, LBUM 300 and LBUM 647) to inhibit the growth of $S$. scabies was studied. Their capacity to alter the expression of thaxtomin biosynthesis genes ( $t x t A$ and $t x t C$ ), nec1 and tomA was also investigated using newly developed TaqMan probe-based quantitative reverse transcription-polymerase chain reaction assays. Pseudomonas sp. LBUM 223 significantly inhibited S. scabies growth and repressed transcription of all targeted genes in the pathogen. S. scabies growth was also significantly inhibited by Pseudomonas sp. LBUM 300; however, this strain failed to alter the expression of any of the targeted genes. Finally, Pseudomonas sp. LBUM 647 was unsuccessful both at inhibiting pathogen growth and at repressing gene transcription in S. scabies. To our knowledge, this is the first demonstration that an antagonistic organism can repress the expression of key genes involved in S. scabies pathogenesis. This capacity is unlikely a trait common to all Pseudomonas spp.
\end{abstract}

Keywords: Common scab of potato; Streptomyces scabies; Pseudomonas sp.; Growth inhibition; Gene expression

Abbreviations: ABI: Applied Biosystems; OBA: Oat Bran Agar; PCA: Phenazine-1-Carboxylic Acid; PCR: polymerase chain reaction; RT: Reverse Transcription; SAS: Statistical Analysis Software

\section{Introduction}

Common scab of potato, caused primarily by Streptomyces scabies [1], prevails in many regions of the world cultivating potato [2], including Canada [3]. Severe symptoms of the disease, described as superficial, raised or sunken necrotic lesions on the tuber's surface [4], render the diseased tubers unmarketable, resulting in important economic losses [3]. Scab-causing streptomycetes induce symptom development on potato tubers by producing thaxtomins $[5,6]$, a family of phytotoxic cyclic dipeptides [7]. Biosynthesis of thaxtomin A, the most potent toxin of the thaxtomin family [8], is carried out by numerous enzymes, including the thaxtomin synthetase TxtA [5] and the mono oxygenase TxtC [9]. The necrogenic protein Nec1, which is involved in the colonization of the infection site, is another virulence factor [10] and the tomatinase TomA, which hydrolyzes the tomato phytoanticipin $\alpha$-tomatine [11], is suspected to be involved in pathogenesis [12].

Some Pseudomonas spp., which are omnipresent soil-inhabiting bacteria [13], are able to protect plants from diseases, such as takeall $[14,15]$ and black root rot [14], through their interaction with the causative plant pathogens. Production of antimicrobial secondary metabolites, such as phenazine-1-carboxylic acid (PCA) [15], 2, 4-diacetylphloroglucinol [14] and hydrogen cyanide [16], enables some strains of Pseudomonas to inhibit the growth of plant pathogens. Other Pseudomonas strains can alter molecular processes leading to the production of pathogenicity and/or virulence factors by the plant pathogen. For example, Pseudomonas strain G degrades a diffusible signal factor required for the expression of virulence factors in the black rot pathogen Xanthomonas campestris pv. campestris $[17,18]$. However, only one study has described Pseudomonas spp.-mediated growth inhibition of plant-pathogenic $S$. scabies [19] and none, to our knowledge, has ever reported on the ability of an antagonistic microorganism to alter the expression of pathogenicity- or virulenceassociated genes in $S$. scabies.

In this study, we sought to evaluate the ability of three Pseudomonas strains to (i) inhibit $S$. scabies growth, using plate inhibition assays and to (ii) alter the expression of four pathogenicityand virulence-associated genes (txtA, txtC, nec 1 and tom $A)$ in the pathogen, using newly developed TaqMan probe-based quantitative reverse transcription (RT)-polymerase chain reaction (PCR) assays. Furthermore, we sought to describe the relationship between txtA and $t x t C$ gene expression in $S$. scabies and thaxtomin A production by the pathogen using time-course assays. The Pseudomonas strains studied here (LBUM 223, LBUM 300 and LBUM 647) are capable of inhibiting the growth of many plant pathogens [20,21]. Furthermore, characterization of the Pseudomonas strains revealed that their respective genomes harbor antimicrobial metabolite biosynthesis genes. Pseudomonas sp. LBUM 223 and Pseudomonas sp. LBUM 647 possess the operons for phenazine and hydrogen cyanide biosynthesis, respectively, whereas Pseudomonas sp. LBUM 300 possesses both the 2,4-diacetylphloroglucinol and the hydrogen cyanide biosynthesis operons $[20,21]$.

*Corresponding author: Martin Filion, Université de Moncton, Campus de Moncton, Département de biologie, 18 Antonine-Maillet Ave., Moncton, NB Canada, E1A 3E9, Tel: 506-858-4329; Fax: 506-858-4541; E-mail: martin.filion@ umoncton.ca

Received September 24, 2010; Accepted October 18, 2010; Published October 20, 2010

Citation: St-Onge R, Goyer C, Filion M (2010) Pseudomonas Spp. can Inhibit Streptomyces scabies Growth and Repress the Expression of Genes Involved in Pathogenesis. J Bacteriol Parasitol 1:101. doi:10.4172/2155-9597.1000101

Copyright: (c) 2010 St-Onge R, et al. This is an open-access article distributed under the terms of the Creative Commons Attribution License, which permits unrestricted use, distribution, and reproduction in any medium, provided the original author and source are credited. 


\section{Materials and Methods}

\section{Bacterial strains used in this study}

S. scabies strain LBUM 848 [22] and Pseudomonas strains LBUM 223, LBUM 300 and LBUM $647[20,21]$ are described elsewhere.

\section{Plate inhibition assays}

Four treatments were prepared in triplicate, for a total of 12 samples: (i) $S$. scabies only (no antagonist), (ii) $S$. scabies and LBUM 223, (iii) S. scabies and LBUM 300 and (iv) S. scabies and LBUM 647. S. scabies and each Pseudomonas strain were grown in $10 \mathrm{ml}$ of oat bran broth ( $\mathrm{pH} 7.2)$, prepared as described previously [23] and 10 $\mathrm{ml}$ of tryptic soy broth (BD, Mississauga, ON, Canada), respectively. Cultures were incubated with continuous shaking at $28^{\circ} \mathrm{C}$ for 6 days (S. scabies) or $24 \mathrm{~h}$ (Pseudomonas strains). A $100-\mu \mathrm{l}$ aliquot of $S$. scabies culture was spread onto $20-\mathrm{ml}$ oat bran agar (OBA) plates $(100 \times 15 \mathrm{~mm})$. OBA medium (pH 7.2) was prepared as described previously [23]. After briefly air-drying plates, a $20-\mu$ l aliquot of Pseudomonas sp. culture, containing approximately $7.3 \times 10^{7} \mathrm{CFU}$, was spotted on the surface of the medium in the center of the plate. Plates were randomized (complete randomized bloc design) and incubated at $28^{\circ} \mathrm{C}$ for 6 days. The inhibition zone (distance between the edge of the antagonist spot and that of the vegetative mycelium growth inhibition area) was measured and total RNA was extracted from all the $S$. scabies mycelia and spores established on the plate. The experiment was performed three times.

\section{RNA extractions and DNase treatments}

Total RNA was extracted from S. scabies cells using the Ultraclean Microbial RNA Isolation kit (MO BIO Laboratories, Carlsbad, CA, USA). Mycelia and spores of the pathogen were retrieved from OBA plates by gently scrapping the surface of the medium with a sterile metal spatula. Cells were transferred into Micro RNA Bead Tubes, to which were then added 300 and $15 \mu$ l of solutions MR1 and MR2, respectively. The remaining extraction steps were performed essentially as described by the manufacturer; however, a supplementary cell homogenization step, using a Fast Prep FP120 (Qbiogene, Carlsbad, CA, USA) at a speed of 5.5 for $45 \mathrm{~s}$, was performed prior to the vortex homogenization step. Co-extracted DNA was digested using the TURBO DNA-free and DNA-free kits (Ambion, Austin, TX, USA), as described previously [21]. Thorough removal of DNA was confirmed using real-time quantitative PCR (data not shown). RNA was stored at $-80^{\circ} \mathrm{C}$.

\section{Time-course assays}

txtA and $t x t C$ gene expression levels in $S$. scabies and thaxtomin A production were assessed every $24 \mathrm{~h}$ over the course of 10 days. Studies were carried out in quadruplicates, for a total of 44 samples. A $100-\mu \mathrm{l}$ aliquot of $S$. scabies culture, prepared as described above, was spread onto OBA plates. Plates were randomized (complete randomized bloc design) and incubated at $28^{\circ} \mathrm{C}$. The "Day 0" plates were placed at $4^{\circ} \mathrm{C}$ immediately following plate inoculation until thaxtomin extractions (at approximately $4 \mathrm{~h}$ post-inoculation). At each sampling date, the morphological differentiation stage of $S$. scabies (vegetative and aerial mycelium growth, spore formation) was noted. Total RNA was extracted from $S$. scabies once mycelium growth had sufficiently progressed (starting at 3 days post-inoculation). At each time point, thaxtomins were extracted from the OBA medium following total RNA extraction (if any).

\section{Thaxtomin a extraction and quantification}

Following the retrieval of $S$. scabies cells for total RNA extraction, the remaining OBA medium was crushed in $40 \mathrm{ml}$ of ethyl acetate for 1 min using a Polytron PT 10-35 homogenizer (Kinematica, Bohemia, NY, USA) at a speed of 2.5. The resulting slurry was centrifuged at $2,000 \mathrm{x} \mathrm{g}$ for $5 \mathrm{~min}\left(4^{\circ} \mathrm{C}\right)$. The supernatant was recovered and treated with anhydrous sodium sulphate in order to remove all traces of water. The ethyl acetate extract was then recovered by filtration through a Whatman filter paper and the ethyl acetate was allowed to evaporate completely under a closed fume hood. Extracts were stored at $4^{\circ} \mathrm{C}$ until processed. Dried extracts were re-dissolved in 1.0 $\mathrm{ml}$ of water: acetonitrile (73:27), filtered through $0.45-\mu \mathrm{m}$ syringe filters and injected into a Supelco LC-18 column $(4.6 \times 150 \mathrm{~mm})$ using a Rheodyne Model 7125 injector with a $20-\mu$ l sample loop. The highperformance liquid chromatography system consisted of a Series 1100 quaternary pump (Agilent Technologies, Wilmington, DE, USA), a Gilson 118 UVNis detector (Gilson Medical Electronics, Middleton, WI, USA) and Class VP chromatographic software (Shimadzu Scientific Instruments, Columbia, MD, USA). The mobile phase was water: acetonitrile (73:27), at a flow rate of $1.0 \mathrm{ml} / \mathrm{min}$. Thaxtomin was eluted at a retention time of $6.3 \mathrm{~min}$ and was detected at 380 $\mathrm{nm}$. Calibration standards were prepared by dissolving thaxtomin A (provided by R.R. King, Potato Research Center, Agriculture and Agri-

\begin{tabular}{|c|c|c|c|c|}
\hline Targeted gene & Name & & Sequence $5^{\prime} \rightarrow 3^{\prime}$ & Amplicon size (bp) \\
\hline \multirow[t]{3}{*}{ rрoB } & rpoBf & $\mathrm{F}^{\mathrm{a}}$ & CGT CGC CTC CAT CAA GGA & \multirow[t]{3}{*}{68} \\
\hline & $\mathrm{rpoBr}$ & $\mathrm{R}^{\mathrm{a}}$ & GCG GGT TGT TCT GGT CCA T & \\
\hline & rpoBprobe & $\mathrm{Pa}^{a}$ & CTT CGG CAC CAG CCA & \\
\hline \multirow[t]{3}{*}{$t x t A$} & txtAfor & $\mathrm{F}^{\mathrm{a}}$ & TGC TCA ACT CCG TGA TCC AGT A & \multirow[t]{3}{*}{69} \\
\hline & txtArev & $\mathrm{R}^{\mathrm{a}}$ & GGG ACA CCT CGC GCA GTA & \\
\hline & txtAprobe & $\mathrm{Pa}^{a}$ & CCT CAG GCG ATT ACC TGT & \\
\hline \multirow[t]{3}{*}{ txtC } & txtCfor & $\mathrm{F}^{\mathrm{a}}$ & ACC ATC TCG CTG TCC TTG GT & \multirow[t]{3}{*}{61} \\
\hline & txtCrev & $\mathrm{R}^{\mathrm{a}}$ & CGT GGA CGA CGG AGA ACT TC & \\
\hline & txtCprobe & $\mathrm{Pa}^{\mathrm{a}}$ & TTA TGC ACT GCA GCC GG & \\
\hline \multirow[t]{3}{*}{ nec1 } & nec1for & $\mathrm{F}^{\mathrm{a}}$ & GCT TGG GCC GGT ATG CT & \multirow[t]{3}{*}{54} \\
\hline & nec1rev & $\mathrm{R}^{\mathrm{a}}$ & TGC AGG CGA GGT GTT TTA AA & \\
\hline & nec1probe & $\mathrm{Pa}^{\mathrm{a}}$ & CTT CCT GAAAGC GCC & \\
\hline \multirow[t]{3}{*}{ tomA } & tomAfor & $\mathrm{F}^{\mathrm{a}}$ & CCA GAA GCT CGG ACT CGA AGT & \multirow[t]{3}{*}{67} \\
\hline & tomArev & $\mathrm{R}^{\mathrm{a}}$ & CTG CTG ATC CAC GTC GTA GGT & \\
\hline & tomAprobe & $\mathrm{Pa}$ & CGA TCA CCG AAC TCG ACG T & \\
\hline
\end{tabular}

${ }^{\mathrm{a}} \mathbf{F}$, forward primer; $\mathbf{R}$, reverse primer; $\mathbf{P}$, TaqMan probe

Table 1: Sequences of primers and TaqMan probes used in this study. 
Food Canada, Fredericton, NB, Canada) in the mobile phase. A threepoint standard curve yielded a correlation coefficient of 0.9997 . The concentration of stock solutions of thaxtomin A was confirmed using the Beer-Lambert Law and the molecular absorptivity of thaxtomin A in ethanol (4050 at $398 \mathrm{~nm}$ ). An extraction efficiency of $86 \pm 4 \%$ (mean \pm standard deviation, $n=2$ ) was estimated by quantifying extracted thaxtomin A from OBA plates supplemented with $20 \mu \mathrm{g}$ of purified thaxtomin A.

\section{Primer and probe design}

The following sequences were retrieved from the National Center for Biotechnology Information database (http://www.ncbi.nlm.nih. gov/): accession numbers FJ007430-FJ007480 (rpoB), FJ007531FJ007579, AF255732 (txtA), FJ007580-FJ007629, AF393159 (txtC), AM293590, AM293591, AF385166-AF385180 (nec1), FJ007481FJ007529 and AY707079 (tomA). Multiple sequence alignments were performed for each data set using the ClustalW function in the BioEdit Sequence Alignment Editor 7.0.4.1 software [24]. PCR primers and TaqMan probes targeting $100 \%$ conserved sequences were designed with Primer Express 3.0 (Applied Biosystems (ABI), Foster City, CA, USA). Probes were labeled with the reporter dye 6-carboxyfluorescein ( $5^{\prime}$ end) and the minor groove binder non-fluorescent quencher $\left(3^{\prime}\right.$ end). Primers and probes were synthesized by Integrated DNA Technologies (Coralville, IA and USA) and ABI, respectively.

\section{Quantitative RT-PCRs}

RNA transcripts of genes $r p o B, t x t A, t x t C$, nec 1 and $\operatorname{tom} A$ were reversely transcribed using the TaqMan Reverse Transcription Reagents kit $(\mathrm{ABI})$ and the reverse primers $\mathrm{rpoBr}$, txtArev, txtCrev, nec1rev and tomArev, respectively (Table 1). Twenty-microliter RT reactions were prepared and carried out in a PTC-200 DNA Engine Thermal Cycler (MJ Research, Waltham, MA, USA), as described by the manufacturer. RT products were stored at $-20^{\circ} \mathrm{C}$. Products were amplified by singleplex quantitative PCR. Twenty-five-microliter reactions, containing $0.2 \mu \mathrm{M}$ of TaqMan probe (Table 1) and $0.5 \mu \mathrm{M}$ each of forward and reverse primer (Table 1), were prepared using the TaqMan PCR Core Reagents kit (ABI) and carried out in triplicate in a 7500 Real Time PCR System (ABI), as described by the manufacturer (50 amplification cycles). A negative control, containing no RT products, was included in each quantitative PCR run. Fluorescence was measured during the extension step.

\section{Data processing}

Data from each experimental replicate were processed independently as follows. Raw fluorescence data were baselinecorrected using the default settings of the 7500 System SDS Software version 1.4 (ABI). Baseline-corrected [25]. For a given gene, calculated midpoints and amplification efficiencies of each individual reaction were averaged among all samples and used to calculate $R_{0}$ values. Gene expression values of the target genes were normalized to those of the endogenous reference gene using the following formula: $R_{0}$ Target gene $/ R_{0 \text { Reference gene. }}$. Fold changes correspond to the quotient of the normalized gene expression value in the treatment and the mean normalized gene expression value in the calibrator. The calibrators of the plate inhibition assays and the time-course studies consisted of the "S. scabies only" and the "Day 3" samples, respectively. Mean fold change values and standard errors were calculated using the Statistical Analysis Software (SAS) 9.1.3 (SAS Institute, Cary, NC, USA, 2002-2003).fluorescence data $(\Delta R n)$ were exported from the SDS software. Amplification plots of the endogenous reference gene $(r p o B)$ and each of the target genes $(t x t A, t x t C$, nec 1 and $t o m A)$ were analyzed using the DART-PCR 1.0 workbook

\section{Statistical analyses}

Plate inhibition assays: Inhibition zones data were ranktransformed. Relative fold change values were power-transformed $\left(x^{0.0001}\right)$ to ensure normal distribution of residuals and homogeneity of variances. Using the MIXED procedure in SAS, univariate one-way mixed-model analyses of variance were carried out to investigate the effect of the antagonist treatment on (i) $S$. scabies growth in vitro and on (ii) $t x t A$, (iii) $t x t C$, (iv) nec1 and (v) tom $A$ gene expression in the pathogen. The antagonist treatment and the experimental replicate were the fixed and random effects, respectively. A posteriori multiple comparisons of least squared means were performed using the Tukey-Kramer method. $P$ values equal to or smaller than 0.05 were deemed significant. Using the GLM (general linear model) procedure in SAS, a multivariate analysis of variance was undertaken to correct for false-discoveries. The effect of the antagonist treatment on the overall expression of pathogenicity- and virulence-associated genes in the pathogen was investigated. Wilks' lambda statistic was used to ascertain statistical significance.

Time-course studies: Cross-correlations between mean relative txt $A$ and $t x t C$ fold change values and mean thaxtomin A production were evaluated using the cross-correlation function of the ARIMA (autoregressive integrated moving average) procedure of SAS. Correlation coefficients greater than two standard errors were deemed statistically significant.

\section{Results}

\section{Growth inhibition of $S$. scabies}

The ability of Pseudomonas strains LBUM 223, LBUM 300 and LBUM 647 to inhibit $S$. scabies growth was examined. The antagonist treatment significantly affected pathogen growth in vitro $\left(F_{3,30}=\right.$ 135.29; $P<0.01$ ). Of the three Pseudomonas strains tested, only Pseudomonas strains LBUM 223 and LBUM 300 significantly inhibited pathogen growth on OBA medium. Furthermore, the inhibitory activity of Pseudomonas sp. LBUM 223 was significantly greater than that of Pseudomonas sp. LBUM 300 by approximately 30\% (Figure 1).

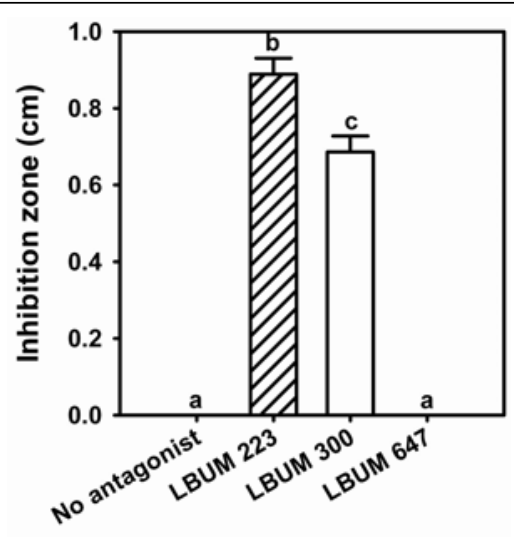

\section{Antagonist treatment}

Figure 1: Growth inhibition of common scab-inducing S. scabies by various Pseudomonas strains. In plate inhibition assays, S. scabies was either grown in the absence of an antagonist or was confronted with a Pseudomonas strain (LBUM 223, LBUM 300 or LBUM 647). Growth inhibition zones were measured after 6 days. Data are presented as mean \pm standard error $(n=9)$. Means of groups annotated with different letters were significantly different $(P<0.05)$. 


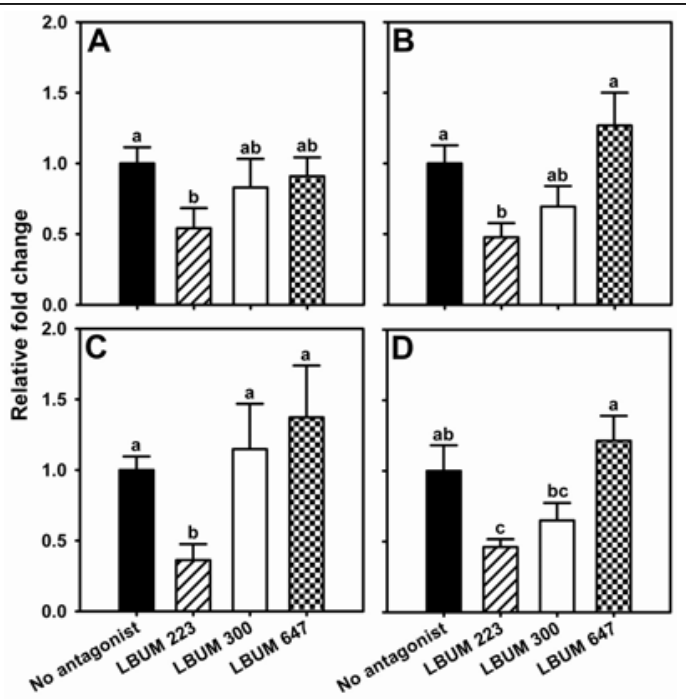

Antagonist treatment

Figure 2: Repression by Pseudomonas strains of pathogenicity- and virulence-associated gene expression in $S$. scabies. In plate inhibition assays, S. scabies was either grown in the absence of an antagonist or was confronted with a Pseudomonas strain (LBUM 223, LBUM 300 or LBUM 647). Transcripts of genes $t x t A(\mathbf{A}), \operatorname{txtC}(\mathbf{B}), \operatorname{nec} 1$ (C) and tomA (D) were quantified in the pathogen after 6 days using quantitative RT-PCR assays. Data are presented as mean \pm standard error $(n=9)$. Means of groups annotated with different letters were significantly different $(P<0.05)$.

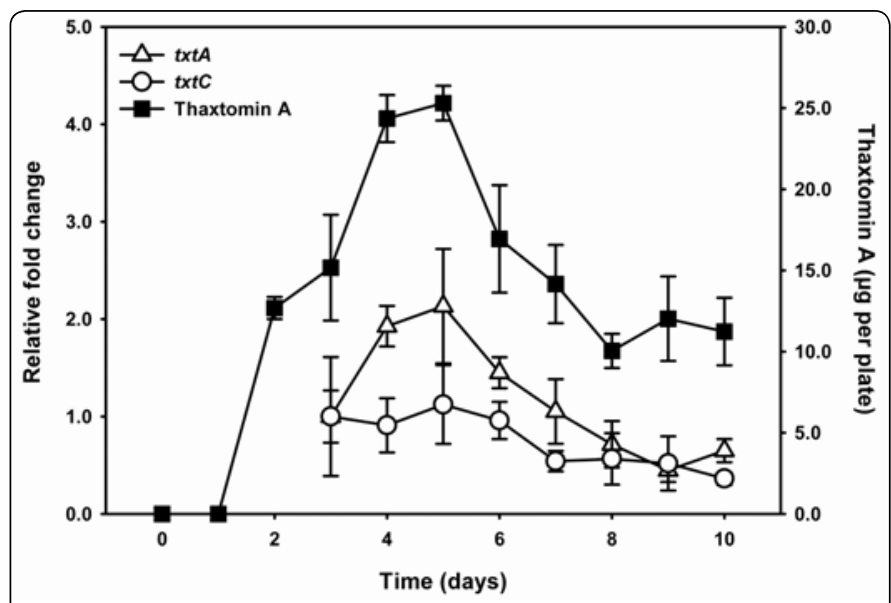

Figure 3: txtA and $t x t C$ gene expression and thaxtomin A production in $S$. scabies over time $t x t A$ and $t x t C$ gene expression was monitored in $S$. scabies every $24 \mathrm{~h}$ over the course of 10 days using quantitative RT-PCR assays. Concurrently, thaxtomin A was quantified in the growth medium using highperformance liquid chromatography. All data are presented as mean \pm standard error $(n=4)$.

\section{txtA, $t \times t C$, nec1 and tom $A$ gene expression in $S$. scabies}

The ability of the three Pseudomonas strains to alter the expression of four pathogenicity- and virulence-associated genes in the pathogen was also investigated. The antagonist treatment significantly altered the expression of $\operatorname{txt} A\left(F_{3,29}=3.74 ; P=0.02\right)$, $\operatorname{txtC}\left(F_{3,29}=6.94 ; P<0.01\right), \operatorname{nec} 1\left(F_{3,29}=8.50 ; P<0.01\right)$ and $\operatorname{tom} A$ $\left(F_{3,29}=7.42 ; P<0.01\right)$. Transcription levels of txtA, txtC, nec 1 and tomA in S. scabies confronted with Pseudomonas sp. LBUM 223 were significantly lower than those noted in the pathogen grown in the absence of an antagonist by approximately 46, 52, 64 and $54 \%$, respectively (Figure 2). In contrast, transcription levels of the four pathogenicity- and virulence-associated genes in $S$. scabies confronted with either Pseudomonas sp. LBUM 300 or Pseudomonas sp. LBUM 647 did not significantly differ from those noted in the pathogen grown in the absence of an antagonist (Figure 2). The multivariate analysis further corroborated the above results (results not shown).

\section{$t x t A$ and $t x t C$ gene expression and thaxtomin A production over time}

A time-course study was undertaken to assess the correlation between $t x t A$ and $t x t C$ gene expression and thaxtomin A production (Figure 3). Thaxtomin A production was first detected at 2 days postinoculation at the onset of aerial mycelium growth. It increased from day 2 to day 5 and then generally decreased. Thaxtomin $\mathrm{A}$ was detected at all sampling dates from day 2 to day 10. txtA and txtC gene transcripts were detected from day 3 to day 10 . Gene expression was not investigated prior to day 3 as sufficient amounts of biological material were not available for total RNA extractions. Cross-correlations were used to determine the correlation between the trends in thaxtomin biosynthesis gene expression and those in thaxtomin A production. txtA and txtC gene expression were significantly cross-correlated $(\mathrm{R}=0.81)$ and both $t x t A$ gene expression and txtC gene expression were significantly crosscorrelated with thaxtomin A production $(R=0.97$ and $R=0.79$, respectively). In general, mean thaxtomin $A$ production as well as mean $t x t A$ and $t x t C$ gene expression levels reached a maximum at day 5 , then generally decreased. No time-delayed effects were noted, indicating that production of thaxtomin A closely followed $t x t A$ and txtC gene expression.

\section{Discussion}

In this study, three Pseudomonas strains were investigated for their ability to (i) inhibit the growth of common scab-inducing $S$. scabies and to (ii) alter the expression of four pathogenicity- and virulence-related genes in this pathogen. Pseudomonas strains LBUM 223 and LBUM 300 effectively inhibited the growth of $S$. scabies in vitro. As Pseudomonas sp. LBUM 647 failed to inhibit S. scabies growth, the ability to affect growth of the target organism is unlikely a trait common to all antagonistic Pseudomonas spp.

Pseudomonas sp. LBUM 223 was also able to repress the expression of the pathogenicity- and virulence-associated genes txtA, txtC, nec1 and tomA, whereas Pseudomonas strains LBUM 300 and LBUM 647 were unable to significantly alter the expression of any of these investigated genes. To our knowledge, repression of genes involved in $S$. scabies pathogenesis by another antagonistic organism has never been demonstrated. Reactions catalyzed by the thaxtomin synthetase TxtA [5] and the mono oxygenase TxtC [9] are crucial to the synthesis of the plant toxin thaxtomin A by scabcausing streptomycetes. The reduction in thaxtomin A production by $S$. scabies resulting from a decrease in $t x t A$ and $t x t C$ gene expression (this study) would likely lessen pathogen virulence. It has been demonstrated previously that strain virulence on potato is positively correlated with the quantities of thaxtomin A produced [26].

Many bacteria can control plant diseases by altering molecular processes leading to the production of pathogenicity and/or virulence factors by the pathogen. For example, Bacillus thuringiensis subsp. israelensis B23 suppresses Erwinia carotovora-induced soft rot development on potato tuber slices in part by degrading $\mathrm{N}$-acylhomoserine lactones [27] which are required for the expression of virulence factors in the pathogen [28]. Expression of the gene 
aiiA (encoding the $N$-acylhomoserine lactonase responsible for the inactivation of $\mathrm{N}$-acylhomoserine lactones) in E. carotovora itself results in a decrease in the production of pectolytic enzymes, virulence factors of this pathogen $[29,30]$. This renders the pathogen avirulent on numerous host plants [29]. In this study, the exact mechanism leading to the repression of pathogenicity- and virulenceassociated genes in $S$. scabies remains unknown.

Pseudomonas sp. LBUM 223 harbors phenazine biosynthesis genes $[20]$ and produces PCA (unpublished results). PCA production by Pseudomonas sp. LBUM 223 may be involved in S. scabies growth inhibition and repression of pathogenicity- and virulence-associated gene expression. The role of PCA in pathogen antagonism is well documented. For example, a Pseudomonas fluorescens strain inhibits the growth of the fungal pathogen Gaeumannomyces graminis var. tritici, the causative agent of take-all of wheat, in part by producing PCA [15]. Although PCA-mediated growth inhibition of different plant pathogens in vitro has been demonstrated [15,31], the involvement of PCA in repressing the expression of pathogenicity- and virulencerelated genes in a plant pathogen has, to our knowledge, yet to be demonstrated. Additional studies are required to better characterize the molecular processes underlying gene repression in $S$. scabies by Pseudomonas spp.

Our results indicate that thaxtomin A production appears to begin during vegetative mycelium growth at the onset of aerial mycelium growth, between 24 and 48 hours post-inoculation. This corroborates results obtained previously [32], which demonstrated that thaxtomin A production begins approximately 24 to 48 hours following the inoculation of oat bran broth with $S$. scabies. Thaxtomin A production peaked during sporulation and decreased thereafter. Interestingly, in this study, decreasing $t x t A$ and $t x t C$ expression appeared to mirror the decrease in thaxtomin A quantity. These results suggest that thaxtomin $\mathrm{A}$ is degraded or modified by the producing S. scabies. Several members of the Streptomyces genus, such as non-pathogenic Streptomyces strains EF-50 and EF-73, are known to be able to degrade thaxtomin A in vitro [33]. Also, it has been previously demonstrated that $S$. scabies isolates produce a de-12- $N$ methyl analogue of thaxtomin $\mathrm{A}$ in oatmeal broth after prolonged incubation, likely by modifying previously produced thaxtomin A [34]. To our knowledge, a relationship between $t x t A$ and $t x t C$ expression, thaxtomin A production and $S$. scabies morphological differentiation stages has not been described previously.

Pseudomonas sp. LBUM 223, which inhibited S. scabies growth and repressed $t x t A, \operatorname{txt} C$, nec 1 and $\operatorname{tom} A$ transcription in the pathogen, showed potential as a biological control agent of common scab. It is impossible at this stage to clearly determine how many different determinants in Pseudomonas sp. LBUM 223 are involved in $S$. scabies growth inhibition and in txtA, txtC, nec1 and tomA gene repression. Thorough characterization of the bacterial interactions occurring between potato-pathogenic $S$. scabies and antagonistic Pseudomonas spp. under in vitro conditions constitutes a first step in determining the potential of these strains to control common scab of potato. Experiments performed under soil conditions represent the next logical step to validate the results obtained in this study. Development of a PCA-nonproducing mutant of Pseudomonas sp. LBUM 223 is currently underway to better address the implication of PCA production in this system.

\section{Acknowledgements}

The authors wish to thank Nadine DeCoste and Amy Novinscak (Université de Moncton) as well as Jean Embleton and Russell R. King (Potato Research Center) for their technical assistance. The authors also thank Gaétan Moreau (Université de Moncton) for the helpful discussion concerning the statistical analyses performed. This study was supported by a Natural Sciences and Engineering Research Council of Canada (NSERC) grant to Martin Filion. A Canada Graduate Scholarship (NSERC) was awarded to Renée St-Onge.

\section{References}

1. Lambert DH, Loria R (1989) Streptomyces scabies sp. nov., nom. rev. Int J Syst Bacteriol 39: 387-392.

2. Locci R (1994) Actinomycetes as plant pathogens. Eur.J.PlantPathol 100: 179200.

3. Hill J, Lazarovits G (2005) A mail survey of growers to estimate potato common scab prevalence and economic loss in Canada. Can J Plant Pathol 27: 46-52.

4. Loria R, Bukhalid RA, Fry BA, King RR (1997) Plant pathogenicity in the genus Streptomyces. Plant Dis 81: 836-846.

5. Healy FG, Wach M, Krasnoff SB, Gibson DM, Loria R (2000) The txtAB genes of the plant pathogen Streptomyces acidiscabies encode a peptide synthetase required for phytotoxin thaxtomin A production and pathogenicity. Mol Microbio 38: 794-804.

6. Lawrence $\mathrm{CH}$, Clark MC, King RR (1990) Induction of common scab symptoms in aseptically cultured potato tubers by the vivotoxin, thaxtomin. Phytopathology 80: 606-608.

7. King RR, Lawrence CH, Clark MC, Calhoun LA (1989) Isolation and characterization of phytotoxins associated with Streptomyces scabies. J Chem Soc Chem Commun 13: 849-850.

8. Hiltunen LH, Laakso I, Chobot V, Hakala KS, Weckman A, et al. (2006) Influence of thaxtomins in different combinations and concentrations on growth of micropropagated potato shoot cultures. J. Agric. Food Chem 54: 3372-3379.

9. Healy FG, Krasnoff SB, Wach M, Gibson DM, Loria R (2002) Involvement of a cytochrome P450 monooxygenase in thaxtomin A biosynthesis by Streptomyces acidiscabies. J Bacteriol 184: 2019-2029.

10. Joshi M, Rong X, Moll S, Kers J, Franco C, et al. (2007) Streptomyces turgidiscabies secretes a novel virulence protein, Nec1, which facilitates infection. Mol Plant Microbe Interact 20: 599-608.

11. Seipke RF, Loria R (2008) Streptomyces scabies $87-22$ possesses a functional tomatinase. J Bacteriol 190: 7684-7692.

12. Loria R, Kers J, Joshi M (2006) Evolution of plant pathogenicity in Streptomyces. Annu Rev Phytopathol 44: 469-487.

13. Weller DM (2007) Pseudomonas biocontrol agents of soilborne pathogens: looking back over 30 years. Phytopathology 97: 250-256

14. Keel C, Schnider U, Maurhofer M, Voisard C, Laville J, et al. (1992) Suppression of root diseases by Pseudomonas fluorescens CHA0: importance of the bacterial secondary metabolite 2,4-diacetylphloroglucinol. Mol Plant Microbe Interact 5: 4-13.

15. Thomashow LS, Weller DM (1988) Role of a phenazine antibiotic from Pseudomonas fluorescens in biological control of Gaeumannomyces graminis var. tritici. J Bacteriol 170: 3499-3508.

16. Ahl P, Voisard C, Défago G (1986) Iron bound-siderophores, cyanic acid and antibiotics involved in suppression of Thielaviopsis basicola by a Pseudomonas fluorescens strain. J. Phytopathol 116: 121-134.

17. Barber CE, Tang JL, Feng JX, Pan MQ, Wilson TJG, et al. (1997) A nove regulatory system required for pathogenicity of Xanthomonas campestris is mediated by a small diffusible signal molecule. Mol Microbiol 24: 555-566.

18. Newman KL, Chatterjee S, Ho KA, Lindow SE (2008) Virulence of plant pathogenic bacteria attenuated by degradation of fatty acid cell-to-cell signaling factors. Mol Plant Microbe Interact 21: 326-334.

19. Sessitsch A, Reiter B, Berg G (2004) Endophytic bacterial communities of fieldgrown potato plants and their plant-growth-promoting and antagonistic abilities. Can. J.Microbiol 50: 239-249.

20. Paulin MM (2007) Étude moléculaire de l'antibiose et de son impact sur des agents phytopathogènes fongiques. M.Sc. Thesis, Université de Moncton, Moncton, NB, Canada.

21. Paulin MM, Novinscak A, St-Arnaud M, Goyer C, DeCoste NJ, et al. (2009) Transcriptional activity of antifungal metabolite-encoding genes phID and hcnBC in Pseudomonas spp. using qRT-PCR. FEMS Microbiol Ecol 68: 212222 
Citation: St-Onge R, Goyer C, Filion M (2010) Pseudomonas Spp. can Inhibit Streptomyces scabies Growth and Repress the Expression of Genes Involved in Pathogenesis. J Bacteriol Parasitol 1:101. doi:10.4172/2155-9597.1000101

Page 6 of 6

22. St-Onge R, Goyer C, Coffin R, Filion M (2008) Genetic diversity of Streptomyces spp. causing common scab of potato in eastern Canada. Syst. Appl. Microbiol 31: 474-484.

23. Goyer C, Vachon J, Beaulieu C (1998) Pathogenicity of Streptomyces scabies mutants altered in thaxtomin A production. Phytopathology 88: 442-445.

24. Hall TA (1999) BioEdit: a user-friendly biological sequence alignment editor and analysis program for Windows 95/98/NT. Nucleic Acids Symp Ser 41:95-98.

25. Peirson SN, Butler JN, Foster RG (2003) Experimental validation of novel and conventional approaches to quantitative real-time PCR data analysis. Nucleic Acids Res 31: e73.

26. Kinkel LL, Bowers JH, Shimizu K, Neeno-Eckwall EC, Schottel JL (1998) Quantitative relationships among thaxtomin A production, potato scab severity and fatty acid composition in Streptomyces. Can. J.Microbiol 44: 768-776.

27. Dong Y-H, Zhang X-F, Xu J-L, Zhang L-H (2004) Insecticidal Bacillus thuringiensis silences Erwinia carotovora virulence by a new form of microbial antagonism, signal interference. Appl Environ Microbiol 70: 954-960.

28. Newton JA, Fray RG (2004) Integration of environmental and host-derived signals with quorum sensing during plant-microbe interactions. Cell Microbiol 6: 213-224.
29. Dong Y-H, Xu J-L, Li X-Z, Zhang L-H (2000) AiiA, an enzyme that inactivates the acylhomoserine lactone quorum-sensing signal and attenuates the virulence of Erwinia carotovora. Proc Natl Acad Sci USA 97: 3526-3531.

30. Dong Y-H, Wang L-H, Xu J-L, Zhang H-B, Zhang X-F, et al. (2001) Quenching quorum-sensing-dependent bacterial infection by an $\mathrm{N}$-acyl homoserine lactonase. Nature 411: 813-817.

31. Brisbane PG, Janik LJ, Tate ME, Warren RFO (1987) Revised structure for the phenazine antibiotic from Pseudomonas fluorescens 2-79 (NRRL B-15132). Antimicrob Agents Chemother 31: 1967-1971.

32. Beauséjour J, Goyer C, Vachon J, Beaulieu C (1999) Production of thaxtomin A by Streptomyces scabies strains in plant extract containing media. Can J Microbiol 45: 764-768.

33. Doumbou CL, Akimov V, Beaulieu C (1998) Selection and characterization of microorganisms utilizing thaxtomin A, a phytotoxin produced by Streptomyces scabies. Appl Environ Microbiol 64: 4313-4316.

34. King RR, Lawrence $\mathrm{CH}$ (1996) Characterization of new thaxtomin A analogues generated in vitro by Streptomyces scabies. J Agric Food Chem 44:1108-1110. 